
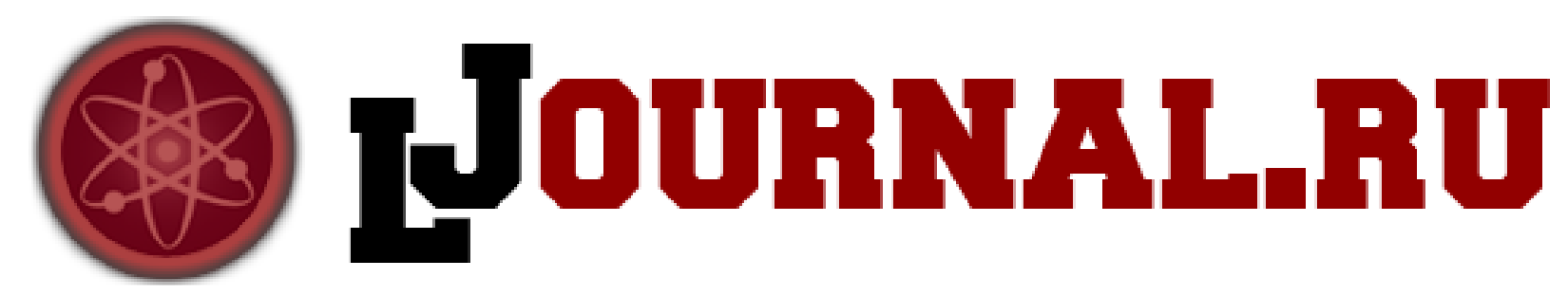

Суворов М.Н.

Российский государственный аграрный университет - МСХА им. К.А. Тимирязева Институт механики и энергетики им. В.П. Горячкина Москва, Россия

doi: 10.18411/1j2016-2-25

\title{
Газопоршневые установки для электроснабжения и варианты их использования сельскохозяйственными потребителями
}

В результате отсутствия финансирования сельского хозяйства, большой доли импортных товаров, сельское хозяйство нашей страны на протяжении 25 лет переживает кризис. Привлекательность жизни на селе в результате чего очень маленькая. Сельские электрические сети, когда-то принадлежавшие совхозам, колхозам, находятся в удовлетворительном состоянии. Зачастую такие сети не имеют собственника, признаются безхозными и передаются на баланс крупным сетевым организациям. На такие электросети электросетевые организации вынуждены затрачивать дополнительные капитальные вложения и ресурсы и этот фактор влияет на цену Квт*ч для сельского потребителя.

Для удобной и конкурентной жизни на селе, в первую очередь современному человеку необходима развитая инфраструктура. Надежное и качественное электроснабжение, газоснабжение и теплоснабжение играют немаловажную роль в развитии современной инфраструктуры. Эти блага цивилизации являются неотъемлемой составляющей привлекательности жизни на селе. Так же, на ряду с развитием централизованного электроснабжения, в нашей стане в первые десятилетия XXI века наращивается уровень газификации села. [7] 
В последние годы руководством нашей страны интенсивно решается задача газификации России. Этот аспект заставляет обратиться к распределенной генерации электрической энергии с использованием природного газа. Особенно интересен вопрос использования газопоршневых установок или газовых микротурбин в удаленных населенных пунктах нашей страны. Там где имеется сложность строительства линий электропередач, там где есть сложность их обслуживания на всей протяженности, альтернативой может стать уже проложенная газовая труба с газопоршневой установкой для генерации электроэнергии. Наличие природного газа способствовало потребителю отказаться от дровяного отопления, а теперь может стать отличной альтернативой централизованному электроснабжению. При этом потери электрической энергии, которые имеются в протяженных линиях электропередач, при схеме распределенной генерации с помощью газопоршневых установок практически равны нулю.

Такие установки имеют ряд несомненных достоинств: относительно низкие удельные капитальные затраты, короткие сроки монтажа, быстрый запуск, простота обслуживания, высокий КПД при частичных нагрузках, мобильность [3]. Наибольшей экономичностью отличаются установки, оснащенные теплообменными агрегатами для утилизации тепла (мини-ТЭЦ) [4].

Газопоршневые двигатели применяемые в электроагрегатах мощностью 30-350 кВ создаются, как правило, на базе быстроходного (1500 об/мин вала двигателя, что соответствует частоте переменного тока 50 Гц) дизелей автотракторного типа. Базовый дизель в большинстве случаев оснащен системой турбонаддува. Применение турбонаддува в газовом двигателе обеспечивает высокие удельные мощностные, экономические и массогаборитные показатели электроагрегата, что особенно важно в случае использования в качестве моторного топлива не только природного газа, но и генераторный газ с низким энергосодержанием. При мощности до 100кВ возможно создание газового двигателя с приемлемыми характеристиками и на базе атмосферного дизеля. 
Газопоршневые двигатели, используемые в качестве привода электрогенератора, различают по трем основным признакам:

• по числу тактов - двух и четырехтактные;

- по способу смесеобразования - внешнее (с использованием газового карбюратора или газовой форсунки во впускном коллекторе) и внутреннее ( с подачей газа непосредственно в цилиндр);

- по способу воспламенения рабочей смеси - искровое зажигание, зажигание от воспламеняющей дозы жидкого дизельного топлива (газодизель), форкамерно - факельное зажигание.

В настоящее время в подавляющем большинстве случаев в качестве привода газопоршневых электроагрегатов мощностью до 350кВ используются быстроходные четырехтактные газовые двигатели $\quad$ с внешним смесеобразованием, с воспламенением рабочей смеси от искры.

Общеизвестно, что с точки зрения эффективности использования энергии газового топлива цикл с подводом тепла по изохоре наиболее выгоден для всех поршневых двигателей. Теоритический цикл газопоршневого двигателя с внешним смесеобразованием и воспламенением от искры отличается от действительного полным и мгновенным (при $\mathrm{V}=\mathrm{const}$ ) тепловыделением. Термический КПД такого цикла $\eta_{\mathrm{t}}$ зависит лишь от степени сжатия $\varepsilon$ и вида рабочего тела (показатель адиабаты k):

$$
\eta_{t}=1-1 / \varepsilon^{k-1}
$$

Разница теоретического и действительно (индикаторного) $\eta_{i}$ КПД циклов характерезует величину потерь вследствие неполноты и несвоевременности сгорания. В современной теории двигателей принято оценивать совершенство рабочего цикла не разностью $\left(\eta_{\mathrm{t}}-\eta_{\mathrm{i}}\right)$, а относительным КПД:

$$
\eta_{\text {отн. }}=\eta_{\mathrm{i}} / \eta_{\mathrm{t}}
$$

Если опустить промежуточные рассуждения, изложенные в работе [4], выражение для относительного КПД можно записать как 


$$
\eta_{\text {отн. }}=\eta_{\text {отн.действ. }} \cdot \eta_{\text {сг }},
$$

соответственно для действительного КПД

$$
\eta_{i}=\eta_{\text {отн.действ. }} \cdot \eta \cdot \eta_{t}
$$

В представленных выражениях $\eta_{\text {сг }}$ характерезует потери тепла за период выгорания топлива (в основном за счет химического недогорания и теплоотвода к стенкам камеры сгорания) и равен коэффициенту активного тепловыделения (коэффициент активного тепловыделения равен отношению количества активного тепла, (т.е. тепла использованного на увеличение внутренней энергии и совершение работы сгоревших газов) к количеству тепла, введенного в цикл с топливом [5]) к концу сгорания всего топлива.

Действительный относительный КПД показывает степень приближения действительного термодинамического цикла к теоретическому и характерезует совершенство использования в нем выделившегося активного тепла по сравнению с теоретическим циклом $\mathrm{V}=$ const при мгновенном тепловыделении в верхней мертвой точке [4].

Эффективный КПД двигателя $\eta_{\mathrm{e}}$ показывает степень совершенства преобразования внесенной с топливом теплоты в механическую работу и зависит от механического КПД $\eta_{\mathrm{M}}$ :

$$
\eta_{\mathrm{e}}=\eta_{i} \cdot \eta_{\mathrm{M}}
$$

Электрический КПД газопоршневого электроагрегата показывет степень совершенства преобразования внесенной с топливом теплоты в электроэнергию и зависит от степени совершенства электрогенератора (электромеханический КПД генератора $\left.\eta_{э м г ~}\right)$ :

$$
\eta_{\text {эл }}=\eta_{\mathrm{e}} \cdot \eta_{\text {эмг }},
$$

или

$$
\eta_{\text {эл }}=\eta_{i} \cdot \eta_{\mathrm{M}} \cdot \eta_{\text {эмг }} \cdot
$$

Последнее выражение показывает, что повышение топливной эффективности газопоршневых электроагрегатов необходимо осуществлять за счет: 
- совершенствования рабочего процесса двигателя: выбора максимально возможной степени сжатия, оптимизации формы камеры сгорания, повышения скорости и полноты сгорания, использования обедненной газовоздушной смеси и сочетании с интенсификацией процесса еe воспламенения $[1,2,5]$;

- снижение доли механических потерь самого двигателя, прежде всего, путем уменьшения рабочего объема двигателя с одновременным использованием повышенного давления наддува с обязательным предварительным охлаждением газовоздушной смеси;

- совершенствования конструкции электрического генератора, снижения механических и электрических потерь.

При испытаниях электроагрегата электрический КПД определяется путем измерения активной электрической мощности на клеммах генератора и расхода газового топлива:

$$
\eta_{\text {эл }}=3600 \cdot N_{\text {эл }} /\left(H_{u} \times Q_{r}\right),
$$

где $N_{\text {эл }}$ - активная электрическая мощность на клеммах генератора, кВт; $H_{u}$ - низшая теплотворная способность газового топлива, МДж/нм ${ }^{3} ; Q_{r}$ расход газового топлива $\mathrm{HM}^{3} /$ ч.

Заслуживают внимания результаты длительной эксплуатации газопоршневых электростанций при их работе на природном газе. Так имеется опыт длительной эксплуатации (Оренбургская область, нефтедобывающее предприятие) газопоршневой электростанции АГ - 60 мощностью 60кВт на базе двигателя ЯМЗ (ОАО «НАТИ»). Наибольшее количество отказов вызвано неисправностями системы зажигания и электронного регулятора. После 14 тыс. и 26 тыс. моточасов производилась замена головок цилиндров (износ седел и тарелок клапанов). Износ вкладышей, поршней, колец, зеркала гильз практически отсутствовал. В целом отзыв о работоспособности станции положительный [6]. 
По материалам работы [8] два газопоршневых электроагрегата АГ-315 (газовый двигатель ЯМ3-8401, конвертация дизеля в газовый двигатель выполнена специалистами ОАО «НАТИ») в составе энергокомплекса эксплатируется на Дачно-Репинском нефтяном месторождении (Оренбургская область) с 2008 г., используя в качестве топлива нефтяной попутный газ. По сведениям, полученным от инженеров энергокомплекса, наработка каждого электроагрегата составила около 30 тыс. моточасов.

Газопоршневая электростанция типа ДГ -98 мощностью 1 МВт (OAO «РУМО», г. Н. Новгород) длительно эксплатируется в ОАО «Камчатэнерго».

Известен опыт эксплуатации мини-ТЭЦ сервисного центра «Тойота» (г. Москва). Здесь установлены два модуля компании «Caterpillar» мощностью 630кВт каждый. По информации полученной от руководителя эксплуатационной службы, за время работы мини-ТЭЦ серьезных проблем не возникало. Техническое обслуживание проводится специалистами регионального дилера «Caterpillar»[9].

Надежность отечественных газопоршневых установок на базе конвертированных дизелей ЯМЗ при работе на природном газе достаточна высока и не уступает зарубежным производителям.

Прежде чем делать выводы, целесообразно или нет использование природного газа и такая схема электроснабжения сельского потребителя, необходимо поставить определенную задачу и решить ряд вопросов. Задачей является: обоснование наилучшего варианта электроснабжения сельского потребителя на территории проживания или деятельности которого уже функционирует или будет построена газовая сеть.

Для решения такой задачи необходимо проанализировать существующие схемы электроснабжения сельских потребителей. Затем разработать стратегии (варианты) использования газопоршневых установок в схеме электроснабжения сельского потребителя.

Исходя из анализа существующих схем электроснабжения сельских 
потребителей были разработаны и предложены для дальнейшего исследования следующие варианты - $\varphi_{i}$ использования газопоршневых установок:

$\varphi_{1}$ - установка газопоршневых электроагрегатов в качестве основного источника питания с резервом от существующей ВЛ 6-10кВ и силовых трансформаторов 6- 10/0,4кВ;

$\varphi_{2}$ - установка газопоршневых электроагрегатов в качестве резервного источника питания, основное питание потребителя пот существующей ВЛ 610кВ и силовых трансформаторов 6-10/0,4кВ;

$\varphi_{3}$ - совместное питание потребителей (питание от газопоршневых установок и от существующей ВЛ 6-10кВ и силовых трансформаторов 610/0,4кВ.

Далее предстоит выбрать критерии по которым будет оцениваться эффективность, надежность работы существующей электросети, либо сети с использованием газопоршневых установок. Также необходимо выбрать критерии по которым будет оцениваться качество электрической энергии, получаемой от электросетевой компании, либо от генератора с газопоршневым двигателем. Кроме этих двух основных критериев необходимо рассмотреть долговечность, затраты на обслуживание, безопасность, при наличии статистических данных. Критериев оценки может быть любое количество, на усмотрение исследователя или лица принимающего решение. Задача в этом случае становится многокритериальной.

Следующий вопрос, который предстоит решить - это неопределенность исходной информации о нагрузке потребителя, которая может как увеличиваться, так и уменьшаться, так же о стоимости кВт*ч электроэнергии и о стоимости м3 природного газа. В этом случае задача превращается в многокритериальную задачу, решаемую в условиях неопределенности исходной информации. Такие задачи решаются, как правило, на основе теории решений, а наиболее вероятный метод раскрытия неопределенности, является метод, основанный на теории нечетких множеств, использующий экспертные оценки 
состояний среды. Сбор и анализ экспертных мнений (оценок) является исследовательской задачей лица принимающего решение.

В наше время, благодаря наличию огромных запасов природного газа на территории нашей страны, наличию положительного опыта эксплуатации газопоршневых электроагрегатов, исходя из состояния сельских электросетей можно смело говорить о возможности внедрения газопоршневых установок (ГПУ) в качестве как основных, так и резервных источников электроснабжения сельских потребителей. 
M.N. Suvorov

Institute of mechanics and energetics named after V.P. Goryachkin Russian State Agrarian University - Moscow Agricultural Academy named after

K.A. Timiryazev

Moscow

\section{Gas reciprocating units for electricity supply and alternatives of their usage by agricultural consumers.}

The article is about the current state of rural electrical network, the current infrastructure of the village, the attractiveness of rural life, the prospects of gasification of inhabited Russian localities. Types of gas reciprocating units, variants of their usage for electricity supply of agricultural consumers are presented in the article. The article states about the method of search of the best alternative on the basis of various criteria under conditions of uncertain initial information.

The advantages of gas reciprocating units are considered: relatively low specific capital costs, short installation time, drystart, ease of maintenance, high efficiency output at fractional load, mobility.

The article deals with the conditions for effective efficiency output of gas reciprocating engines, which measures could improve fuel efficiency of gas reciprocating generator units.

The article presents examples of long-term exploration of gas engine power plants running on natural gas.

Options of using of gas reciprocating units for power supply of agricultural consumers are presented in this work. The further choice of criteria for different alternatives of use of gas reciprocating units for electricity supply of agricultural consumers. According to these criteria will be evaluated the effectiveness, the reliability of existing electrical power network or networks with using of gas reciprocating units, the quality of electric power received from the electric grid company or from generator with gas reciprocating engine, durability, maintenance costs, safety. The question of the uncertainty of the initial information about consumer load is put, the load may increase or decrease, the cost of $k W / h$ of electricity and $m 3$ of natural gas cost are also reviewed. The method of removal of the uncertainty of the initial information is proposed. 


\section{Литература:}

1. Воинов А.Н. Сгорание в быстроходных поршневых двигателях. - М: Машиностроение, 1977. - 277с.

2. Генкин К.И. Газовые двигатели. - М: Машиностроение, 1977. - 196с.

3. Зайченко В.М., Цой А.Д., Штеренберг А.Я. Распределенное производство энергии. - М.: БуКос, 2008. - 207с.

4. Зайченко В.М., Чернявский А.А. Мини-ТЭЦ на базе газопоршневых двигателей //АГЗК+АТ.2011. - №5 (59). - С. 99-103.

5. Стечкин Б.С. Генкин К.И., Золотаревский И.В. Индикаторная диаграмма, динамика тепловыделения и рабочий цикл быстроходного поршневого двигателя. - М.: Изд. АН СССР, 1960. - 199с.

6. Лупачев П.Д. Газовые двигатели для тракторов и стационарных установок //Тракторы и сельхозмашины. - 1996. -С. 8-10.

7. Суворов М.Н. Автономные источники электроснабжения с использованием газопоршневых установок в сельском хозяйстве: состояние и дальнейшее развитие// Инновации и инвестиции. - 2015. - №4. - С. 150-152.

8. Журнал «Энергосовет» №4 (23), 2012 [Электронный pecypc], -http: www.energosovet.ru/bul_stat.php?idd=309_ статья в интернете.

9. Опыт эксплуатации мини-ТЭЦ в России // Экологические системы. 2008, №1 [Электронный pecypc], - : http:www.esco.co.ua/journal/2008_1/art168.htm статья в интернете. 